\author{
Giovanni Simonetti \\ Roberto Gandini \\ Francesco Versaci \\ Enrico Pampana \\ Sebastiano Fabiano \\ Matteo Stefanini \\ Alessio Spinelli \\ Carlo Andrea Reale \\ Massimiliano Di Primio \\ Eleonora Gaspari
}

\section{Carotid artery stenting: a single-centre experience with up to 8 years' follow-up}

Received: 11 February 2008

Revised: 12 August 2008

Accepted: 18 August 2008

Published online: 6 November 2008

(C) European Society of Radiology 2008

G. Simonetti · R. Gandini •

E. Pampana $\cdot$ S. Fabiano $\cdot$

M. Stefanini $(\bowtie) \cdot A$. Spinelli .

C. A. Reale - M. Di Primio - E. Gaspari

Department of Diagnostic Imaging,

Molecular Imaging, Interventional

Radiology and Radiation Therapy,

University Hospital "Tor Vergata",

81 Oxford Street,

00133 Rome, Italy

e-mail: matteostefanini@hotmail.com

Tel.: +39-620-902401

Fax: +39-620-902404

F. Versaci

Department of Internal Medicine,

Unit of Cardiology,

University Hospital "Tor Vergata",

81 Oxford Street,

00133 Rome, Italy
Abstract Carotid artery stenting (CAS) may be an alternative to surgical endoarterectomy not only in highrisk patients. We report results in the endovascular treatment of carotid artery disease with up to 8 years' follow-up. In this retrospective study, we analysed data from 853 consecutive patients (946 arteries) treated for carotid artery stenosis between April 1999 and March 2007; 491 (52\%) arteries were symptomatic and 455 (48\%) were asymptomatic. Preprocedural evaluation of the patients was performed with echo Doppler, magnetic resonance angiography (MRA) or computed tomographic angiography (CTA) and a neurological examination. A cerebral protection device was used in $879(92.9 \%)$ procedures. Anti-platelet therapy was administered before and after the procedure. All patients were included in a follow- up of up to 8 years. Technical success was achieved in $943(99.6 \%)$ lesions. At 30 days, there was a $0.21 \%(n=2)$ death rate, a $0.42 \%$ major stroke rate, a $1.69 \%$ minor stroke/transient ischaemic attack (TIA) rate and a combined $2.32 \%$ TIA/stroke and death rate. During follow-up, echo Doppler evidenced restenosis in 39 (4.85\%) cases; of these, only five, presenting restenosis $>80 \%$, were treated with an endovascular reintervention. At the long-term follow-up, two strokes $(0.23 \%)$ were reported, which both occurred within the first 2 years. In our experience, carotid artery stenting seems to be a safe and effective treatment, providing satisfactory long-term clinical results.

Keywords Stents - Angioplasty · Carotid stenosis $\cdot$ Restenosis .

Follow-up

\section{Introduction}

Stroke is the third most common cause of death in the United States, causing one in every 16 deaths in 2004 [1].

Of 700,000 strokes that occur each year, $20 \%$ are due to carotid artery disease and its economic burden was estimated by the American Heart Association to be $\$ 51$ billion, considering direct and indirect costs, in 1999 [2].

In Europe, cerebral vascular accidents affect $235 / 100,000$ individuals, equivalent to $1,070,000$ new stroke events every year [3].

Large population-based studies indicate that the prevalence of carotid stenosis ranges from approximately $0.5 \%$ in individuals above the age of 60 and $10 \%$ in those above
80 years; however, stenosis remains asymptomatic in the majority of cases [4-6].

The incidence of stroke will probably increase in the next 20 years due to the aging of the population and the improved survival rate of patients with previous acute stroke or myocardial infarction, who are at increased risk of further vascular accidents.

Randomized controlled trials have shown that surgical treatment of carotid artery stenosis is more efficient than medical therapy alone in terms of stroke prevention when treating carotid artery stenosis $>70 \%$ in asymptomatic patients or $>50 \%$ in symptomatic patients [7-12].

The major trials on carotid endarterectomy (CEA) report the following periprocedural stroke/death risk rates at 
30 days: in symptomatic patients, NASCET reports a $6.7 \%$ rate for stenosis $>70 \%$ and ECST a $7 \%$ for stenosis $>80 \%$; regarding asymptomatic patients, ACST and VACS report $3.1 \%$ and $4.7 \%$ rates, respectively; while ACAS, which considers low-risk patients, reports a $2.3 \%$ rate [7-11].

On the basis of 30-day post-procedure results of clinical trials on CEA, the American Heart Association considers acceptable a morbidity and mortality rate up to $3 \%$ in asymptomatic patients and up to $6 \%$ in symptomatic patients [13].

Even though the majority of single-centre studies assessed the safety and efficacy of carotid artery stenting (CAS) in the treatment of carotid artery disease, randomized trials that compare CEA with CAS report discordant results. While in the CAVATAS and SAPPHIRE studies the periprocedural complication rate (stroke and death) of CEA and CAS are comparable with a greater risk/benefit ratio in patients at high risk for surgery; EVA-3S reported a higher complication rate in CAS [14-16].

In this study, we report the short- and long-term clinical results we obtained in the treatment of 946 consecutive arteries with CAS and retrospectively evaluate its efficacy and safety in our experience.

\section{Materials and methods}

Patient population

We retrospectively analysed data regarding 853 consecutive patients (946 arteries) with internal carotid artery stenosis who, between April 1999 and March 2007, underwent carotid artery stenting with the use of a cerebral protection device in 879 arteries $(92.9 \%)$.

\section{Inclusion/exclusion criteria}

Inclusion criteria were:

- Symptomatic patient with a stenosis $\geq 50 \%$

- Asymptomatic patient with a stenosis $\geq 80 \%$ with positive computed tomographic angiography (CTA) or magnetic resonance angiography (MRA) for silent cerebral chronic ischemia ipsilateral to the stenosis

- Asymptomatic patient with a stenosis $\geq 80 \%$ with negative CTA or MRA for cerebral chronic ischemia but with Doppler ultrasound, CTA or MRA findings demonstrating a vulnerable plaque (after 2003 also confirmed by dedicated microcoil MR study)

- Asymptomatic patient with a stenosis $\geq 80 \%$ with negative CTA or MRA for cerebral chronic ischemia but with a fast progression of the degree of the stenosis

- Cases considered unsuitable for CEA because at high risk for surgery
- Cases in which CEA was abandoned due to critical EEG alterations after carotid artery clamping during the procedures

\section{Exclusion criteria were:}

- Previous stroke within 3 weeks prior to CAS

- Leucopenia, neutropenia

- Gastrointestinal bleeding in the previous 3 months

- Angiographic evidence of a fresh thrombus for the high embolization risk

- Long preocclusive lesion (“string sign" lesion) because of the high restenosis rate due to the total length of the stent and to the reperfusion damage risk.

- Contraindications to anti-platelet therapy

All patients provided signed informed consent and agreed to undergo regular follow-up evaluation.

Pre-procedural evaluation

All patients underwent pre-procedural neurological examination performed by an independent team of neurologists. The indication for stenting was given by echo-colour Doppler (ECD) and digital subtraction angiography (DSA) in 35 cases $(3.69 \%)$, ECD and CTA multislice examination in 532 cases $(56.25 \%)$, by ECD and MRA examination in 190 cases $(20.1 \%)$ and by ECD associated to both CTA and MRA in 189 cases (19.96\%). MR and CT were performed to evaluate the morphology of the aortic arch, the level and degree of the stenosis, the intracranial vascular anatomy and cerebral parenchyma.

We studied the plaque's morphology with MR microscopy using dedicated micro-coils in 53 cases $(5,60 \%)$ and intravascular ultrasound (IVUS) in $12(1.26 \%)$; the results of these evaluations have been used to plan the procedure and to choose the most appropriate materials selecting the correct protection device, the size and features of the stent and balloon.

Of the arteries examined, $491(52.00 \%)$ were classified as symptomatic because the patients presented a transient ischemic attack or stroke within the 6 months prior to the stenting procedure, and $455(48 \%)$ were classified as asymptomatic. The demographics, clinical evaluation and neurological history of the patient population are reported in Table 1.

\section{Drug therapy}

Pre-procedural therapy consisted in the administration in the 4 days prior to the intervention of aspirin $(100 \mathrm{mg} /$ day $)$ in association with clopidogrel $(75 \mathrm{mg} /$ day $)$ in 908 cases $(95.98 \%)$ or with ticlopidine $(500 \mathrm{mg} /$ day) in 38 cases $(4.02 \%)$.

During the procedure, intra-arterial heparin (5000 IU) was administered. To prevent bradycardia and hypotension 
Table 1 Demographic data

\begin{tabular}{ll}
\hline Male & $494(58 \%)$ \\
Female & $359(42 \%)$ \\
Age (years) & \\
Mean & $70 \pm 14$ \\
Range & $55-83$ \\
Symptomatics with stenosis $\geq 50 \%$ & $491(52 \%)$ \\
Major stroke & $9(3 \%)$ \\
Minor stroke & $112(23 \%)$ \\
Transient ischaemic attack (TIA) & $368(75 \%)$ \\
Asymptomatics with stenosis $\geq 70 \%$ & $455(48 \%)$ \\
Previous omolateral CEA & $103(12.07 \%)$ \\
Controlateral carotid occlusion & $87(10.19 \%)$ \\
Dislypidemia & $609(71.39 \%)$ \\
Diabetes mellitus & $326(38.21 \%)$ \\
COPD & $192(22.5 \%)$ \\
Hypertension & $794(93.08 \%)$ \\
Smokers & $371(43.49 \%)$ \\
Acute myocardial infarction & $106(12.42 \%)$ \\
ESRD & $24(2.81 \%)$ \\
\hline
\end{tabular}

during balloon inflation and stent deployment, prophylactic atropine $(0.5-1 \mathrm{mg})$ administration was performed in all patients $1 \mathrm{~min}$ before stent deployment. Following the procedure, all patients were prescribed lifelong aspirin (100 mg/day) therapy. Aspirin was associated with clopidogrel $(75 \mathrm{mg} /$ day $)$ or ticlopidine $(500 \mathrm{mg} /$ day $)$ for the first 6 weeks in 879 cases. In 67 cases, due to co-morbidities, lifelong co-therapy was prescribed.

\section{Stenting procedure}

All procedures were performed in an angiographic room; patients were assisted by an anaesthesiologist for invasive arterial pressure measurement and oxymetry monitorization; the patients, under light sedation, were kept conscious. Procedures were performed by two highly experienced interventional radiologists.

The site of percutaneous approach, protection device and stent type were chosen by the operator after pre-procedural vascular imaging evaluation. The femoral artery was chosen as the access site in 922 procedures (97.77\%); in 28 cases the brachial artery was chosen as the access site due to the origin from the anonym artery of the left common carotid artery and in two cases of aorto-iliac occlusive disease. Long sheaths (6 or $7 \mathrm{~F}$ ) and a telescopic technique were utilized during the first part of our experience (218 cases). Afterwards we used the direct guiding catheter $(6-7 \mathrm{~F})$ technique to engage the common carotid artery. In both cases the catheters were advanced into the common carotid artery on 0.035 -inch support stiff wires placed in the external carotid artery.

In nine cases, due to the presence of high-grade stenosis at the origin of the internal carotid artery, a 3-F microcatheter with hydrophilic 0.021 -inch guidewire was used to advance the guidewire over the stenosis with subsequent predilatation of the stenosis, filter protection device placement and stent deployment. In 24 cases, due to the presence of a high level of creatinine $(2-6 \mathrm{mg} / \mathrm{dl})$ in the routinary blood test, the procedure was performed using gadolinium DOPA (Guerbet), in an amount not exceeding $40 \mathrm{ml}$, as contrast medium.

A filter protection device was used in 879 cases (92.9\%), whereas a stop flow protection was used in 53 cases $(6.02 \%)$ with tight stenosis due to the presence of a 'soft' plaque evaluated at $\mathrm{CT}$ and MR. In 67 patients (7.1\%) no protection device was used; while in 63 of these patients the protection device was not yet available, in four patients it was not possible to advance it through the lesion (Table 2).

In 98 cases $(10.35 \%)$ of sub-occlusive stenosis, a predilation was performed using low-profile balloons (diameter range 3.0-3.5 mm): in nine cases the selected cerebral protection device (CPD) had to be changed because it was impossible to position the protection (five Angioguard and four Filter-wire Ez); in six cases the CPD was changed and successfully positioned, whereas in three cases the procedure was performed without protection.

In 946 arteries a single self-expandable stent was implanted to cover the entire lesion, in ten cases two overlapping stents were placed (Table 3 ).

In $889(94 \%)$ procedures, the stent was placed with its proximal end in the common carotid artery and its distal end in the internal carotid artery. In eight cases the stent was deployed in the internal carotid artery and in nine cases in the common carotid artery. All stents were post-dilated with non-compliant balloons (range 5-6 mm). The average fluoroscopy time (from the local anaesthetic infiltration to the removal of introducer) was $5.3 \mathrm{~min}$ (range 3.6-28 min) with a significant procedural time reduction in the last patients thanks to an evolution of the materials and the acquired experience. In all cases, after stent deployment, a

Table 2 Encephalic protection devices

\begin{tabular}{lll}
\hline Cerebral protection device & Procedures & $\%$ \\
\hline Firewire EZ & 671 & $76.33 \%$ \\
Accunet & 70 & $7.96 \%$ \\
Mo.Ma & 53 & $6.02 \%$ \\
Spider RX & 38 & $4.32 \%$ \\
EmboShield & 24 & $2.73 \%$ \\
Angioguard RX & 23 & $2.61 \%$ \\
No cerebral protection device & 67 & $7.1 \%$ \\
\hline
\end{tabular}


Table 3 Stent type

\begin{tabular}{lll}
\hline Self-expandable stents & Procedures & $\%$ \\
\hline Carotid Wallstent & 611 & $64.58 \%$ \\
RX Acculink & 140 & $14.79 \%$ \\
Xact & 98 & $10.35 \%$ \\
Protegè & 34 & $3.59 \%$ \\
Vivexx & 57 & $6.02 \%$ \\
Precise RX & 13 & $1.37 \%$ \\
Cristallo & 3 & $0.31 \%$ \\
\hline
\end{tabular}

post-procedural angiography was performed to evaluate the eventual residual stenosis and the intracranial circulation. Manual compression was used in 894 cases and a closure system in 52 .

Definitions and follow-up

Technical success was defined as the successful deployment of the stent with a residual stenosis inferior to $30 \%$ with no alterations in the intracranial circulation at the postprocedural angiography. All patients underwent neurological examination the day after the procedure.

Post-procedural complications, according to Mathur et al. [17] classification, were defined as follows:

1. Transient ischemic attack (TIA), any neurological deficit that completely resolved within $24 \mathrm{~h}$

2. Minor stroke, any new neurological deficit that either persisted after $24 \mathrm{~h}$ but completely resolved within 7 days or increased the National Institutes of Health stroke scale by 3 points

3. Major stroke, any new neurological deficit that persisted after 30 days and increased the National Institutes of Health stroke scale by 3 points

4. Myocardial infarction, occurrence of a new Q-wave in two leads and the presence of elevated creatine kinase (CK) or CK-MB, or occurrence of a CK elevation twofold the upper normal limit in the presence of an elevated CK-MB

The follow-up we performed consisted in a neurological evaluation at 1 and 6 months and every year after the procedure. Stent patency and in-stent restenosis (ISR) were assessed by ECD in all patients at 1, 3,6 months and every 12 months after the procedure. A restenosis is considered of $50 \%$ for values of peak systolic velocity (PSV) $\geq 240 \mathrm{~cm} / \mathrm{s}$ and PSVR (internal carotid artery/common carotid artery ratio) $245 \mathrm{~cm} / \mathrm{s}$; restenosis $\geq 70 \%$ were diagnosed by $\mathrm{PSV} \geq 350 \mathrm{~cm} / \mathrm{s}$.

In all cases in which a restenosis was shown at ECD, a multislice CT evaluation was performed with the use of Advanced Vessel Analysis to confirm the degree of the restenosis.

\section{Statistical evaluation}

We retrospectively analysed data recorded in a digital archive which included information on our patients from their admission to the last check-up they underwent.

\section{Results}

The total study population consisted of 853 patients (946 arteries): 494 were men and 359 women; average age was $69 \pm 14$ years, range $55-83$ years; $14.06 \%$ were $\geq 80$ years old. Of the arteries treated, $455(48.00 \%)$ were asymptomatic and $491(52.00 \%)$ symptomatic. In our study population, risk factors correlated with atheromasic disease were: male gender (57.91\%, median age 69 years), dyslipidemia $(71.39 \%)$, diabetes mellitus $(38.21 \%)$, hypertension $(93.08 \%)$, cigarette smoking $(43.49 \%)$, recent myocardial infarction $(12.42 \%)$.

\section{Procedural results}

Technical success was achieved in 943 (99.6\%) cases with no significant stenosis after the procedure. In three cases $(0.31 \%)$ with tight stenosis due to ulcerated calcified plaque at a tortuous internal carotid artery origin, it was not possible to cross the lesion.

In 30 cases $(3.17 \%)$ an internal carotid artery spasm was observed, probably caused by the distal part of the filter device.

Three TIAs $(0.31 \%)$ were observed during the procedures, all in symptomatic patients. A symptomatic patient had an intra-procedural minor stroke $(0.11 \%)$.

Periprocedural results (within 30 days)

At 30 days, eight $(0.85 \%)$ TIAs were observed. In five $(0.53 \%)$ cases TIA occurred within the first $24 \mathrm{~h}$ after stenting, probably due to distal embolization; of these TIAs, three occurred in symptomatic and two in asymptomatic patients. In all cases, pre-procedural diagnostic evaluation showed mainly soft plaques and a postprocedural check of the filter device revealed a large amount of debris. Of the other three $(0.31 \%)$ TIAs that occurred within the first 30 days, one was observed in a symptomatic patient and two in asymptomatic individuals.

Of the four $(0.42 \%)$ minor strokes that occurred in the same period, one was observed in a symptomatic patient and another one in an asymptomatic patient within the first $24 \mathrm{~h}$ after the intervention. Of the remaining two observed minor strokes, one occurred in a symptomatic and one in an asymptomatic patient

Within the first month after the procedure, four $(0.42 \%)$ major strokes were observed, of which one was within $24 \mathrm{~h}$ 
in a symptomatic patient. Two major strokes occurred in asymptomatic patients and one in a symptomatic patient.

Two $(0.21 \%)$ patients died: one died due to myocardial infarction within the first $24 \mathrm{~h}$, while the other died 3 weeks after the intervention due to a major stroke that occurred 24 $\mathrm{h}$ after the procedure.

Our data reveal that there is no significant difference between asymptomatic $(0.48 \%)$ and symptomatic patients $(0.66 \%)$ in terms of stroke/death incidence at 30 days. In our study non-Q myocardial infarctions were registered in only ten patients $(1.17 \%)$ (Table 4$)$.

\section{Long-term follow-up}

Long-term follow-up was based on neurological examination and ECD evaluation.

At 1 year follow-up, two strokes $(0.23 \%)$ were reported: one in a symptomatic patient, the other in an asymptomatic patient; both have been evaluated as minor strokes at the neurological examination. Both patients were affected by dyslipidemia, one was a diabetic smoker, the other one was obese, affected by a psychiatric disease and therefore uncompliant to anti-platelet therapy. Overall, two TIAs $(0.28 \%)$ occurred, one during the first year, the other in the second year of follow-up. No additional strokes were diagnosed in the following years (Table 4). No procedurerelated death occurred during the long-term follow-up.

During follow-up, between the first and second year, an occlusion of the stent occurred in two patients; in one case two overlapped stents had been deployed during the procedure and in the other case the patient had been treated for post-CEA symptomatic restenosis.

Thirty-nine restenosis $(4.85 \%)$ were diagnosed at ECD evaluation during follow-up: among these 11 presented with severe stenosis (greater than $80 \%$ ). Only five symptomatic patients underwent a further CAS procedure: in three cases a cutting balloon was used after percutaneous transluminal angioplasty (PTA) was performed, and in two patients a stent intrastent was placed; all five procedures were performed with the use of a cerebral protection device.

The data analysis shows how the highest restenosis incidence rate occurs in the period between the first month
$(1.79 \%)$ and the first year $(0.78 \%)$ after the procedure (Table 5).

Some risk factors, such as as smoke, diabetes mellitus and others listed in Table 2, have been analysed with reference to restenosis rates, thus emphasizing the high significance of smoke $(p<0.000, \mathrm{OR}=12.47,95 \% \mathrm{CI}=$ 4.74-32.79) and diabetes mellitus $(p<0.025, \mathrm{OR}=2.82$, $95 \% \mathrm{CI}=1.13-7.15)$ as high-risk factors for restenosis occurrence. Considering the characteristics of the plaque evaluated with CT and, in the last period, with MR microscopy, it has also been confirmed that, as reported by other authors, mainly calcified concentric plaques represent a high-risk factor for restenosis development $(p<0.01, \mathrm{OR}=$ $3.53,95 \% \mathrm{CI}=1.31-9.32)$. Calcified concentric plaque presence can be considered as a high-risk factor for restenosis probably due to resistance it offers to the stents' radial force.

Our study evidenced a particular subgroup of patients that present higher restenosis occurrence. A retrospective evaluation showed that 11 of 103 patients that had previously undergone CEA for carotid artery disease presented post-CAS restenosis, which occurred in only 28 out of 843 that underwent CAS as the primary treatment. Statistical analysis confirmed that post-CEA restenosis is a negative prognostic factor for post-CAS restenosis $(p<0.005, \mathrm{OR}=5.99,95 \% \mathrm{CI}=2.33-15.26)$.

\section{Discussion}

Since the mid 1990s, the technique has evolved mostly due to the development of cerebral protection systems, to the miniaturization of the devices, to the evolution of dedicated stents and to pre- and post-procedural anti-platelet therapy standardization

Many recent non-randomized studies demonstrate that CAS, with the use of cerebral protection devices, is a safe and effective treatment in the management of carotid artery stenosis [18, 19-24].

The indications for CAS have grown as well. As described in the proCAS registry, while initially CAS was considered a valid alternative to endarterectomy only in patients at high risk for surgery, it is now indicated for all patients affected by atherosclerotic carotid artery disease [25].

Table 4 Intra- and post-procedural results

\begin{tabular}{|c|c|c|c|c|}
\hline Number of arteries & $\begin{array}{l}\text { Intraprocedural } \\
946\end{array}$ & $\begin{array}{l}\text { At } 30 \text { days } \\
944\end{array}$ & $\begin{array}{l}\text { At } 1 \text { year } \\
856\end{array}$ & $\begin{array}{l}\text { At } 2 \text { years } \\
609\end{array}$ \\
\hline TIA & $3(0.31 \%)$ & $8(0.85 \%)$ & $1(0.12 \%)$ & $1(0.16 \%)$ \\
\hline Minor stroke & $1(0.11 \%)$ & $4(0.42 \%)$ & $2(0.23 \%)$ & 0 \\
\hline Major stroke & 0 & $4(0.42 \%)$ & 0 & 0 \\
\hline Death & 0 & $2(0.21 \%)^{\mathrm{a}}$ & 0 & 0 \\
\hline
\end{tabular}

${ }^{\mathrm{a} B o t h}$ deaths occured in patients that presented monolateral stenosis 
Table 5 Restenosis clinical events and rate at follow-up

\begin{tabular}{lll}
\hline 1 month & 6 months & 12 months \\
Arteries: 944 & Arteries: 856 & Arteries: 770 \\
Restenosis CAS: $11(1.16 \%)$ & Restenosis CAS: $10(1.17 \%)$ & Restenosis CAS: $4(0.52 \%)$ \\
Restenosis CAS post CEA:6 $(0.63 \%)$ & Restenosis CAS post CEA:3 $(0.35 \%)$ & Restenosis CAS post CEA: $2(0.26 \%)$ \\
24 months & 36 months & 48 months \\
Arteries: 609 & Arteries: 421 & Arteries: 274 \\
Restenosis CAS: $1(0.16 \%)$ & Restenosis CAS: $1(0.24 \%)$ & Restenosis CAS: $1(0.36 \%)$ \\
Restenosis CAS post CEA: - & Restenosis CAS post CEA: - & Restenosis CAS post CEA: - \\
60 months & 72 months & 96 months \\
Arteries: 200 & Arteries: 73 & Arteries: 35 \\
Restenosis CAS: - & Restenosis CAS: - & Restenosis CAS: - \\
Restenosis CAS post CEA: - & Restenosis CAS post CEA: - & Restenosis CAS post CEA: - \\
\hline
\end{tabular}

The first prospective multicentre randomized trial comparing surgical with endovascular treatment of patients with symptomatic carotid stenosis was the CAVATAS (Carotid and Vertebral Transluminal Angioplasty Study) that considered 251 patients treated with angioplasty. Even though obsolete from a technical point of view, since $74 \%$ of the patients affected by carotid artery stenosis were treated with angioplasty and only $26 \%$ with PTA-stent without cerebral protection devices, this trial gave satisfactory results. At 30 days, the mortality rate and major stroke risk appeared to be comparable in both techniques- $10 \%$ after endovascular treatment and $9.9 \%$ after endarterectomy - as well as the efficacy in the prevention of ictus. Regarding minor complications, this study shows that the endovascular treatment gives statistically better results compared with surgery; this demonstrates that the endovascular approach, even without any protection device, offers clinical results comparable with those of surgery [14].

These data are further supported by SAPPHIRE that compared CAS with CEA in patients at high risk for surgery. In this randomized trial, 156 patients were treated with CAS with the use of a cerebral protection device and 151 with CEA. The death/stroke rate in the group of patients treated with CAS was $4.5 \%$ and in the one of patients treated with CEA $6.6 \%$; such results go beyond the limits set by AHA guidelines, which are based on ACAS and NASCET; this may be explained by the fact that these latter studies exclude patients presenting controlateral carotid occlusions, restenosis after CEA, age above 80 years or the presence of concomitant cardiovascular pathologies. The study shows how an endovascular approach gives comparable results, in terms of morbidity and mortality rates at 24 months, with those of endarterectomy [15].

The most recent randomized trial, EVA-3S, which compared the two techniques, has reported results in disagreement with the trend of monocentric studies, with a CAS stroke/death rate of $9.6 \%$ at 30 days. This study gave post-CEA complication results comparable with those in the literature (3.9\% stroke/TIA at 30 days).
From what has been described, it appears clear that the biggest limitations of the study are the scarce endovascular technique experience of the operators (12 carotid artery stentings or 35 procedures performed on supra-aortic trunks, of which five were carotid) and the preprocedural anti-platelet therapy which was only recommended and not always homogeneously administered. Double anti-platelet therapy was administered to $82.9 \%$ of the patients and only $85.4 \%$ were administered anti-platelet therapy after the intervention [16].

The results of this randomized trial appear to be in disagreement and considerably inferior to those of our study, in which the major complications rate at 30 days is $1.21 \%$ in symptomatic patients and $1.09 \%$ in asymptomatics, making a total of $2.3 \%$, and with the survey by Bosiers et al. [18], in which the major stroke/death rate is $1.4 \%$ in symptomatics and $1 \%$ in asymptomatics.

Such discrepancy can be ascribed to the scarce operator experience and to the exclusively recommended use of double pre- and post-procedural anti-platelet therapy. It has been demonstrated how the use of coplidogrel and ASA double anti-platelet therapy reduces the risk of embolization [26].

SPACE trial failed as well to demonstrate the "noninferiority" of the endovascular treatment compared with CEA, reporting a complication (stroke/death) rate at 30 days of $7.68 \%$ for CAS and $6.51 \%$ for CEA.

Such high rates may be due to the limited use of cerebral protection devices, which were employed in only $27 \%$ of the interventions, as well as to the scarce operator experience required ( 25 consecutive successful angioplasty or stent procedures) [28].

Analysing the cited studies with the largest records of cases, we consider that many of the technical failures are due to the lack of a pre-procedural evaluation of the aortic arch and of the vascular anatomy of the epiaortic vessels, which in our experience has led to a drastic reduction of technical failures and of the procedural time, which can be considered important in the reduction of intra-procedural 
complication rate. Furthermore, we believe the importance of the CAS learning curve to be one of the most critical topics in the evaluation of complications. It therefore remains fundamental to associate the operators' experience with a correct pre-procedural evaluation performed with the available diagnostic methods to assess detailed information on the stenosis extension, vascular anatomy and the type of plaque. These data influence the choice of the kind of approach and of the most appropriate and safe materials [27].

In our experience, none of the selected patients was excluded due to comorbities, so all patients considered at high surgical risk were treated in the absence of major complications. Therefore, among 946 procedures, the combined complication rate (death, major and minor stroke, TIA) at 30 days (including intra- and postprocedural complications) was $2.32 \%$, resulting lower than that of most single group experiences but comparable with that reported in the review by Goodney et al. [27] and the experience of Reimers et al. [22].

There were no significant differences regarding major complications (death, major and minor stroke) between symptomatics and asymptomatics, but a higher major stroke rate has been observed in the high risk for surgery asymptomatics presenting soft plaques, due to embolization within the first $24 \mathrm{~h}$ after the deployment of the stent.

In the group of asymptomatic patients, the major and minor complications rate at 30 days was $1.1 \%(0.88 \%$ minor, $0.22 \%$ major); these data are lower than the maximum acceptability limit for combined postprocedural complications (stroke and death) of 3\% set by the AHA for asymtomatic patients treated with CEA and in agreement with literature data which report a death/major stroke rate at 30 days of $1.2 \%[19,21]$.

Even though in our experience there is predominant use of a single kind of stent, Carotid Wallstent (Boston Scientific, USA), used in $64.58 \%$ and of a single type of cerebral protection device, Filter Wire EZ (Boston Scientific, USA), used in $76.33 \%$, there are no significant differences in long-term results between devices. It has been demonstrated that the presence of a neurological symptomatology is a risk factor for the occurance of TIA with a $p<0.05$ significance, while there is no significant correlation between the presence of neurological symptomatology before the stent placement and the subsequent occurance of stroke. In our experience, the choice of the stent to be used was based both on the patient's anatomy and on the kind of plaque encountered; this strategy is recommended by many authors to allow operators to treat the patient in the most appropriate way.

The use of occlusive protection devices has been limited to few cases presenting plaques with a high risk of embolization. In these patients a CTA or MRA evaluation of the intracranial circulation was performed to assess the absence of fetal anomalies that could have rendered the patients unsuitable to carotid occlusion. Over the last few years, these devices have become more handy, thanks to the reduction of their calibre, which made them more compatible with percutaneous use.

By analysing the examined risk factors, we have detected their significant correlation with the occurrence of restenosis. These are, in particular, smoking, type II diabetes mellitus, the presence of mainly calcific concentric plaques and omolateral restenoses of lesions that have been previously treated with CEA.

Even though the data we have are supported by a small sample, we believe the persistance of such risk factors must be considered a negative prognostic factor due to a higher probability of restenosis. As previously reported, we decided to retreat symptomatic patients presenting restenosis. In all cases the symptomatology that represented was at least a TIA. At further check-up, all re-treated patients were asymptomatic with no signs of significant intimal hyperplasia at ECD and CT evaluations.

Despite the small number of interventions, the results obtained in the retreatment of restenotic lesions allow to assert that the management of these patients does not imply significant complications nor an increase of intraprocedural complications.

\section{Conclusions}

The literature data show that in symptomatic patients, revascularization is more effective than medical therapy alone because it reduces complications.

Since in our experience with asymptomatic patients the advantages of revascularization over medical therapy are not as evident, we believe the simple evaluation of the stenosis rate is not sufficient and characterization of the plaque is necessary to identify lesions that need to be treated.

Our experience shows how correct patient selection, based on clinical data and on an accurate pre-procedural diagnostic evaluation performed with different imaging techniques, and an appropriate stent placement associated with an adequate medical therapy, allow the achievement of a high technical success rate with low peri-procedural complication rates.

The follow-up performed using the most adequate imaging techniques to detect restenosis occurrence at an early stage, and an evaluation of the risk factors for atheromasic disease and plaque genesis, allow a preventive intervention to reduce the incidence of restenosis.

To conclude, we assessed that to obtain satisfactory results in the endovascular treatment of carotid artery disease, the use of accurate diagnostic tools, an adequate medical therapy and high-volume hospital with expert operators are necessary; if these requirements are fulfilled, CAS may be considered as an alternative to surgical treatment. 


\section{References}

1. Rosamond W, Flegal K, Friday G, Furie K, Go A, Greenlund K, Haase N, Ho M, Howard V, Kissela B, Kittner S, Lloyd-Jones D, McDermott M, Meigs J, Moy C, Nichol G, O’Donnell CJ, Roger V, Rumsfeld J, Sorlie P, Steinberger J, Thom T, WasserthielSmoller S, Hong Y; American Heart Association Statistics Committee and Stroke Statistics Subcommittee (2007) Heart disease and stroke statistics2007 update: a report from the American Heart Association Statistics Committee and Stroke Statistics Subcommittee. Circulation 115:e69-e171

2. American Heart Association (2000) Economic cost of cardiovascular disease. http://www.americanheart.org/ statistics/10econom.html. Accessed September 2000

3. Truelsen T, Ekman M, Boysen G (2005) Cost of stroke in Europe. Eur J Neurol 12:78-84

4. Ricci S, Flamini FO, Marini M et al (1991) The prevalence of stenosis of the internal carotid in subjects over 49: a population study. Epidemiol Prev 13:173-176

5. Prati P, Vanuzzo D, Casaroli M, Di Chiara A, De Biasi F, Feruglio GA, Touboul PJ (1992) Prevalence and determinants of carotid atherosclerosis in a general population. Stroke 23:1705-1711

6. O'Leary DH, Polak JF, Kronmal RA, Kittner SJ, Bond MG, Wolfson SK Jr, Bommer W, Price TR, Gardin JM, Savage PJ (1992) Distribution and correlates of sonographically detected carotid artery disease in the Cardiovascular Health Study. The CHS Collaborative Research Group. Stroke 23:1752-1760

7. Barnett HJ, Taylor DW, Eliasziw M et al (1998) Benefit of carotid endarterectomy in patients with symptomatic moderate or severe stenosis. North American Symptomatic Carotid Endarterectomy Trial Collaborators. N Engl J Med 339:1415-1425

8. European Carotid Surgery Trialist's Collaborative Group (1998) Randomised trial of endarterectomy for recently symptomatic carotid stenosis: final results of the MRC European Carotid Surgery Trial (ECST). Lancet 351:1379-1387

9. Halliday A, Mansfield A, Marro J, Peto C, Peto R, Potter J, Thomas D; MRC Asymptomatic Carotid Surgery Trial (ACST) Collaborative Group (2004) Prevention of disabiling and fatal strokes by successful carotid endarterectomy in patients without recent neurological symptoms: randomised controlled trial. Lancet 363:1491-1502
10. Executive Committee for the Asymptomatic Carotid Atherosclerosis Study (1995) Endarterectomy for asymptomatic carotid artery stenosis. JAMA 273:1421-1428

11. Hobson RW, Weiss DG, Fields WS et al (1993) Efficacy of carotid endarterectomy for asymptomatic carotid stenosis: the Vetereans Affairs Coperative Study group (VACS). N Engl J Med 328:221227

12. European Carotid Surgery Trialist's Collaborative Group (1991) Interim results for symptomatic patients with severe $(70-99 \%)$ or with mild (0-29\%) carotid stenosis. Lancet 337:12351243

13. Moore WS, Barnett HJM, Beebe HG et al (1995) Guidelines for carotid endarterectomy. A multidisciplinary consensus statement from the ad hoc Committee, American Heart Association. Stroke 26:188-201

14. Endovascular versus surgical treatment in patients with carotid stenosis in the Carotid and Vertebral Artery Transluminal Angioplasty Study (CAVATAS): a randomized trial (2001) Lancet 357:1729-1791

15. Mozes G, Sullivan TM, TorresRussotto DR, Bower TC, Hoskin TL, Sampaio SM, Gloviczki P, Panneton JM, Noel AA, Cherry KJ Jr (2004) Carotid endarterectomy in SAPPHIREeligible high-risk patients: implications for selecting patients for carotid angioplasty and stenting. J Vasc Surg 39:958-965, discussion 965-966

16. Mas JL, Chatellier G, Beyssen B, Branchereau A, Moulin T, Becquemin JP, Larrue V, Lievre M, Leys M, Leys D, Bonneville JF, Watelet S, Provo JP; EVA-3S Investigators (2006) Endarterectomy versus stenting in patients with symptomatic severe carotid stenosis. N Engl J Med 355:1660-1671

17. Mathur A, Roubin GS, Iyer SS, Piamsonboon C, Liu MW, Gomez CR, Yadav JS, Chastain HD, Fox LM, Dean LS, Vitek JJ (1998) Predictors of stroke complicating carotid artery stenting. Circulation 97:1239-1245

18. Bosiers M, Peeters P, Deloose K, Verbist J, Sievert H, Sugita J et al (2005) Does carotid artery stenting work on the long run: 5-year results in high-volume centers (ELOCAS Registry). J Cardiovasc Surg (Torino) 46:241-247

19. Cremonesi A, Manetti R, Setacci F, Setacci C, Castriota F (2003) Protected carotid stenting clinical advantages and complications of embolic protection devices in 442 consecutive patients. Stroke 34:1936-1943
20. Fox DJ, Moran CJ, Cross DWT, Grubb RL, Rich KM, Chicoine MR, Dacey RG, Derdeyn CP (2002) Long-term outcome after angioplasty for symptomatic extracranial carotid stenosis in poor surgical candidates. Stroke 33:2877-2880

21. Henry M, Polydorou A, Klonaris C, Henry I, Polydorou AD, Hugel M (2007) Carotid angioplasty and stenting under protection. State of the art. Minerva Cardioangiol 55:19-56

22. Reimers B, Schlüter M, Castriota F, Tübler T, Corvaja N, Cernetti C, Manetti R, Picciolo A, Listro F, Di Mario C, Cremonesi A, Schofer J, Colombo A (2004) Routine use of cerebral protection during carotid artery stenting: result of a multicenter registry of 753 patients. Am J Med 116:217222

23. Cremonesi A, Setacci C, Manetti R, De Donato G, Setacci F, Balestra G, Borghesi I, Bianchi P, Castriota F (2005) Carotid angioplasty and stenting: lesion related treatment strategies. EuroInterv 1:289-295

24. Bergeron P, Roux M, Khanoyan P, Douillez V, Bras J, Gay J (2005) Longterm results of carotid stenting are competitive with surgery. J Vasc Surg 41:213-21, discussion 221-222

25. Theiss W, Hermanek P, Mathias K, Ahmadi R, Heuser L, Hoffmann FJ, Kerner R, Leisch F, Sievert H, Von Sommoggy S (2004) Pro-CAS: a prospective registry of carotid angioplasty and stenting. Stroke 35:2134-2139

26. Markus HS, Droste DW, Kaps M, Larrue V, Lees KR, Siebler M, Ringelstein B (2005) Dual antiplatelet therapy with clopidogrel and aspirin in symptomatic carotid stenosis evaluated using doppler embolic signal detection: the Clopidogrel and Aspirin for reduction of Emboli in Symptomatic Carotid Stenosis (CARESS) trial. Circulation 111:2233-2240

27. Goodney PP, Schermerhorn ML, Powell RJ (2006) Current status of carotid artery stenting. J Vasc Surg 43:406-411

28. SPACE Collaborative Group, Ringleb PA, Allenberg J, Brückmann $\mathrm{H}$, Eckstein HH, Fraedrich G, Hartmann M, Hennerici M, Jansen O, Klein G, Kunze A, Marx P, Niederkorn K, Schmiedt W, Solymosi L, Stingele R, Zeumer H, Hacke W (2006) 30 day results from the SPACE trial of stentprotected angioplasty versus carotid endarterectomy in symptomatic patients:a randomised non-inferiority trial. Lancet 368:1239-1247 